La Revue

des Droits

de l'Homme

\section{La Revue des droits de l'homme}

Revue du Centre de recherches et d'études sur les droits fondamentaux

$4 \mid 2013$

Revue des droits de l'homme - $\mathrm{N}^{\circ} 4$

\title{
¿Hacia el control « infra-droit » de la integración efectiva en la normativa de extranjería española?
}

\section{Encarnación La Spina}

\section{OpenEdition}

\section{Journals}

Edición electrónica

URL: http://journals.openedition.org/revdh/450

DOI: $10.4000 /$ revdh.450

ISSN: 2264-119X

Editor

Centre de recherches et d'études sur les droits fondamentaux

\section{Referencia electrónica}

Encarnación La Spina, « ¿Hacia el control « infra-droit » de la integración efectiva en la normativa de extranjería española ? », La Revue des droits de l'homme [En línea], 4 | 2013, Publicado el 12 enero 2014, consultado el 10 julio 2020. URL : http://journals.openedition.org/revdh/450 ; DOI : https://doi.org/ $10.4000 /$ revdh. 450

Este documento fue generado automáticamente el 10 julio 2020.

Tous droits réservés 


\title{
¿Hacia el control « infra-droit » de la integración efectiva en la normativa de extranjería española?
}

\author{
Encarnación La Spina
}

1 Desde el Pacto europeo de inmigración y asilo $2008^{1}$, la actual evolución de las políticas de inmigración común en el contexto europeo se ha caracterizado por una inexistente uniformidad tanto en su dimensión cuantitativa como cualitativa a la hora de gestionar el objetivo de la integración efectiva ${ }^{2}$. Las características del concepto normativo de integración a nivel europeo han recogido y recogen tendencias asimétricas por definición recalcitrantes respecto a la pluralidad, la bidireccionalidad y la multidimensionalidad exigida por los ocho principios marco de la política de integración de la Unión Europea ${ }^{3}$. Sin entrar en discusiones sobre los nexos de unión y la solvencia de los puntos comunes, si es posible advertir que sólo en uno de sus extremos la política de integración en la Unión Europea ha podido llegar a ser simétricamente unívoca y consensuada. Me refiero a la convergencia de medidas de integración obligatorias que se han desarrollado desde el 2008 ya bien en forma de tests de integración o cursos de integración cívica vinculantes con el propósito de gestionar el control de los flujos migratorios de entrada y para aquéllos ya asentados.

2 Actualmente, habida cuenta de la proliferación de las medidas de integración, el desafío conceptual que plantea el uso y abuso de una terminología aparentemente sinonímica sólo ha sido matizada en la práctica en su nomenclatura : contratos, compromisos, acuerdos o esfuerzos de integración en sus diferentes modalidades ${ }^{4}$. En cualquier caso, el intenso debate sobre el grado de integración requerida o el declive de los modelos nacionales de integración ${ }^{5}$, dista mucho de aportar una respuesta formal y coherente a la cuestión planteada ${ }^{6}$, especialmente respecto a la definición discrecional de 
indicadores, estrategias y objetivos para dar seguridad jurídica a aquello que forzosamente viene a ser llamado integración aún no siéndolo.

Sin duda, el caso francés ha sido uno de los ejemplos más contestados en el estudio y gestión de los modelos de integración así como sobre las técnicas legislativas necesarias para dotar al corpus normativo de extranjería de valencias abiertas sobre el objeto y contenido de la integración ${ }^{7}$. Sin embargo, no ha sido el único referente a la hora de trasladar ideas o estrictos parámetros acreditativos de países de vieja trayectoria migratoria pues Alemania y Holanda ${ }^{8}$ también han marcado tendencia a nivel europeo. E, incluso en países mediterráneos como España la irrupción normativa del informe o más bien informes sobre el esfuerzo de integración tras la reforma de la ley de extranjería española ha constituido un auténtico punto de inflexión en la gestión de las políticas migratorias llamadas a alcanzar el éxito del proceso de integración. Esta peculiaridad transforma el caso español en un laboratorio relativamente único para observar al mismo tiempo una voluntad integración con tonos en algunas áreas de la asimilación y en otra exclusión. De hecho, mientras la demanda de asimilación cívica lingusitica ex lege es un poco limitada respecto a otros países como Italia que representan un tipo ideal de integracionismo estatalista, en España se sigue un tipo ideal de integracionismo liberal dado el peso de las Comunidades Autónomas9.

A tal efecto, en este trabajo se llevará a cabo un análisis de la significación y configuración legal de la integración en el corpus normativo de la inmigración en España. Una práctica cuya extensión normativa desde la primera ley de extranjería hasta la actualidad ha ido y parece ir en significativo aumento. Tras un largo periodo de tránsito normativo exento de una detallada concreción jurídica de la integración con una magnitud pareja al referente francés, se ha optado tal y como sostiene Lochak ${ }^{10}$ por el uso del llamado « infra-droit » por medio de la remisión reglamentaria o el reenvío a instrucciones generales. El caso español es una mera fórmula versionada en cierto modo a la baja que se suma al amplio crisol del modus integrandi europeo ${ }^{11}$ pero que aporta dada la descentralización de las competencias autonómicas y la heterogeneidad interna en la aplicación de las políticas de integración social ${ }^{12}$ disímiles ideales de integración versus perfección en un mismo territorio.

De este modo, sin duda, la elección de los informes sobre el esfuerzo de integración y su gestión a nivel autonómico puede ser determinante como herramienta acreditativa para la determinación o denegación de los requisitos exigidos ${ }^{13}$ en el procedimiento administrativo de extranjería ${ }^{14}$ aunque quizás no para saldar el problema conceptual y de coherencia que plantea la integración ${ }^{15}$.

\section{Tránsitos y fases en la configuración de la integración efectiva en la ley de extranjería española}

6 A nivel estatal, las primeras políticas relativas específicamente a la integración de los inmigrantes aparecen en el Plan para la Integración Social de los Inmigrantes de 1994 (PISI), el Programa GRECO 2001-2004 (Programa Global de Coordinación de la Extranjería y la Inmigración en España) y en los dos Planes estratégicos de Ciudadanía e Integración 2007-2010 así como respectivamente 2011-2014 (PECI y PECI II). Unos documentos programáticos que se identifican con las diversas fases de la constitución de la España inmigrante ${ }^{16}$, una fase inicial o embrionaria hasta el 1985, seguida de una 
transformación en un país de inmigración (1986-1999) que se ha consolidado a partir del 2000 hasta el momento actual. Todo ello, con un porcentaje de extranjeros en territorio español situado en torno al $12.1 \%$ de la población empadronada (más de 5,7 millones de personas), es decir, en una proporción muy semejante a la de otros países europeos que han sido tradicionalmente receptores de inmigrantes, convirtiéndose en el segundo Estado miembro de la Unión Europea (UE-27), tras Alemania, por número de residentes extranjeros ${ }^{17}$.

7 Durante la primera fase de gestación de las políticas migratorias, la integración aparece a título de mención pero no queda definida en la LO 7/1985 de 1 de julio sobre derechos y libertades de los extranjeros en España. Una de las posibles concepciones que se podían derivar del propio Preámbulo era una mera integración vinculada a un cierto trato de favor para ciertos colectivos de inmigrantes, por razones principalmente de afinidad cultural y una más restrictiva en cuanto a los derechos de los extranjeros ${ }^{18}$. Sólo una década más tarde, tras el acuerdo del Consejo de Ministros de 2 de diciembre de 1994, se aprueba en España el primer Plan para la integración social de los Inmigrantes que insta al desarrollo de una política activa de inmigración por parte del Gobierno, destacando entre sus líneas de actuación "profundizar en la integración social de los inmigrantes que se establecen en España». Es la primera batería de medidas que tiene en cuenta de la conversión de la realidad española como país de inmigración, y también advierte de la falta de atención prestada a las acciones de integración de los inmigrantes hasta el momento, obviamente más centradas en la gestión del control de los flujos migratorios por su condición de Estado-frontera. Las bases del Plan de 1995 definen la integración como un largo proceso dirigido a conseguir la gradual incorporación y participación de los inmigrantes en la vida económica y social del país de acogida en un clima de respeto y aceptación recíprocos. La política de integración pretendida se fundamenta en un compromiso asumido por cada una de las partes implicadas, de tal manera que la sociedad española adopta una actitud abierta y tolerante con las diferencias y peculiaridades que caracterizan a los distintos grupos de inmigrantes para que éstos a su vez, asuman las normas y valores que sostienen la convivencia democrática ${ }^{19}$.

8 Posteriormente, en una segunda fase de transformación marcada por el Programa GRECO (2001-2004), se presenta un ambicioso instrumento de gestión conjunta del fenomeno migratorio. Entre las diversas líneas de actuación comprendidas, indirectamente se incidía en menor grado sobre el objetivo de la integración social de las personas inmigrantes. De hecho, por medio de una pretensión ambigua en el Programa Global de regulación y coordinación de la extranjería e inmigración aprobado el 30 octubre 2001 el principal cometido era agilizar sustancialmente la integración de los residentes extranjeros en situación irregular y su familia como mecanismo activo para el crecimiento y control demográfico del Estado español. Esto es, la consideración del inmigrante en su globalidad, no sólo como trabajador sino como ciudadano con necesidades en los ámbitos educativo, cultural, sanitario, convivencia territorial y de participación social promoviendo así el diálogo constante entre las diferentes Administraciones públicas y los interlocutores sociales.

9 La retórica de estos documentos programáticos sobre la integración precedería el desarrollo normativo del segundo eje de las políticas de inmigración a partir del 2000, al menos, desde un plano teórico, por medio de la obtención de derechos y deberes semejantes a los de los nacionales, incluyendo medidas en la lucha contra las formas de 
discriminación y los comportamientos racistas y xenófobos que las sustenten. No obstante sólo con la Ley orgánica 4/2000 es cuando la inserción social se incorpora como idea complementaria y segundo pilar de la inmigración por medio del reconocimiento de instrumentos orientados a la integración en la sociedad de acogida y un incipiente estatuto jurídico de derechos políticos y sociales a todos los extranjeros no comunitarios que se encontrasen inscritos en el padrón municipal incluso en situación irregular ${ }^{20}$. Una prioridad que si ha visto limitado el alcance de las condiciones de ejercicio de derechos con la LO 8/2000 al establecer una diferencia fundamental entre el extranjero no comunitario con permiso de residencia o estancia y el extranjero no comunitario que se encuentre en una situación irregular. Posteriormente con la LO 11/2003, por la que para reforzar la integración social de los inmigrantes se incluyen aquellas reformas del código civil necesarias para garantizar la protección de la mujer frente a las nuevas realidades sociales que aparecen con el fenómeno de la inmigración. Sucesivamente en un escaso intervalo temporal la LO 14/2003 reafirma que la integración queda ligada a la consecución de un estatus legal y a tal fin incluyen medidas orientadas a hacer frente al considerable incremento producido por el número de residentes extranjeros en España en los últimos años desde otra óptica. Por ello, su desarrollo reglamentario se refiere a una noción de integración social amplia, necesitada de actuaciones en ámbitos diversos y dirigida tanto a la población inmigrante como autóctona que ha sido desarrollada en la esfera autonómica ${ }^{21}$. Sólo, posteriormente, se lleva a cabo una progresiva concreción explícita del eje de las políticas de integración con las previsiones contenidas en las medidas concretas del Plan Estratégico de Ciudadanía e integración PECI 2006-2010 ${ }^{22}$ y en la reforma articulada por la LO 2/2009.

Primero, un plan pensado hábilmente como un programa integral, que estudiara la inmigración en el Estado español desde una perspectiva sociológica y jurídica, con vistas a analizar las políticas de integración en la Unión Europea y de la Administración española estableciendo los principios de la política de integración básicos : igualdad, ciudadanía e interculturalidad. Segundo, la Ley orgánica $2 / 2009$ de 12 de diciembre ${ }^{23}$, la última reforma, cuyo cometido era plasmar un compromiso teórico con la defensa de los derechos humanos por parte de los poderes públicos con vistas a favorecer la plena integración de los inmigrantes, garantizar la convivencia y la cohesión social entre los inmigrantes y la población autóctona. Además es destacable la importante acomodación normativa que realiza tras los recursos de inconstitucionalidad resueltos por la sentencia del Tribunal Constitucional $236 / 2007^{24}$ y siguientes que la ratificaron donde se declaró la inconstitucionalidad de diferentes artículos de la LO 8/2000, salvo en el caso de la educación no obligatoria (STC 236/2007) y la huelga (STC 269/2007) en que sí se contempla la nulidad de los preceptos.

11 Según el artículo 2 bis y ter de la mencionada ley, las Administraciones Públicas incorporarán el objetivo de la integración entre inmigrantes y sociedad receptora, con carácter transversal a todas las políticas y servicios públicos, promoviendo la participación económica, social, cultural y política de las personas inmigrantes en los términos previstos en la Constitución, en los Estatutos de Autonomía y en las demás leyes, en condiciones de igualdad de trato. Para ello, especialmente, se promueve la extensión de acciones formativas, el conocimiento y respeto de los valores constitucionales y estatutarios de España, de la Unión Europea, así como de los derechos humanos, las libertades públicas, la democracia, la tolerancia y la igualdad entre mujeres y hombres al hilo de medidas específicas y áreas de intervención en los 
anteriores parámetros. De este modo, a sensu contrario, más bien se lleva a cabo una descontextualización de los derechos humanos exigiendo mediante acciones formativas, el conocimiento y respeto de un standard internacional de derechos humanos que en la práctica se niega a los mismos sujetos. En este caso, el peso del esfuerzo de integración recae unilateralmente en el inmigrante y no se valida por la igualdad efectiva de los derechos sino más bien por el vaciamiento de garantías jurídicas en la aplicación de la ley de extranjería para aquéllos que ven vulnerados o restringidos sus derechos fundamentales de modo sistemático por el mero hecho de acceder de forma diferente a los derechos y ser excluidos de la ciudadanía ${ }^{25}$.

12 Así en su dimensión jurídica, por primera vez, más allá del nomen iuris de la normativa de extranjería ${ }^{26}$ se concreta directamente la integración y se tiende a ligarla preferentemente a parámetros idiomáticos, laborales y de educación de los menores. En el Título Preliminar se introduce un nuevo artículo 2 bis en el que se define la política migratoria, los principios y ejes de actuación de la misma en un marco competencial remodelado, y bajo un nuevo artículo 2 ter que ordena los principios y actuaciones en materia de integración de los inmigrantes. Tales ejes de acción se materializan en el artículo 31.7 de la ley de extranjería respecto a los procedimientos de renovación de ciertas autorizaciones de residencia temporal de los extranjeros. Se incluye así la valoración especial del "Esfuerzo de integración », que deberá ser acreditado por un informe positivo emitido por la Comunidad Autónoma que certifique la asistencia a las acciones formativas contempladas en el artículo 2 ter de la misma norma.

13 Todo ello, sin perjuicio de la evolución del verdadero punto de inflexión de las políticas de integración más próximo a la veta contractual europea y que ha sido gestado en dos momentos y bajo parámetros diferentes, posiblemente abiertos a una tercera fase. El primero con el RD 557/2011 al establecer la posibilidad de presentar cuatro tipos de informes, entre ellos el informe acreditativo del esfuerzo de integración, emitidos por la Comunidad Autónoma del lugar de residencia del extranjero, a petición suya. Tanto en caso de la renovación de autorizaciones de residencia temporal no lucrativa (art. 51.6 Reglamento), por reagrupación familiar (art. 61.7 Reglamento), renovación de autorizaciones de residencia temporal y trabajo por cuenta ajena (art. 71.6 Reglamento), así como por cuenta propia (art. 109.6 Reglamento). Dicho informe no tiene que presentarse obligatoriamente -por el momento- pero puede ser alegado por el extranjero en caso de no acreditar el cumplimiento de alguno de los requisitos normativamente previstos para la renovación de la autorización y será tenido en cuenta como información a valorar por la oficina de extranjería.

Esta aparente versión sutil del modelo contractual francés se perfila en un segundo momento (seguramente no el último, habida cuenta de la Instrucción SGIE/2/2012 27 ), con la actualmente derogada Instrucción DGI/SGRJ/8/2011 de aplicación del Reglamento de la Ley orgánica $4 / 2000$ sobre derechos y libertades de los extranjeros en España y su integración social en materia de informes sobre esfuerzo de integración. Bajo la fórmula "cabrá la valoración únicamente » se defiende su no exigibilidad obligatoria para la renovación de autorizaciones de residencia temporal o de residencia temporal y trabajo aunque sí se prevé la participación pero no la superación de acciones formativas de entidades públicas o privadas acreditadas, que puede sumarse a otros aspectos requeridos en cada Comunidad autónoma para la directa integración. Dada su temporal naturaleza atípica permite conferir a los informes de integración un potencial efecto de subsanación de los requisitos no acreditados que puede dar 
cobertura a esta ulterior valoración. Se cumple así una incoherencia puesto que cumple una lógica de last chance o suplementaria para requisitos de difícil acreditación o prueba en la praxis ${ }^{28}$.

Esta cierta renovación y apuesta continuista en el eje de las políticas de integración que será modificada por nuevos mecanismos como previsto en la Instrucción SGIE/2/2012 se combina también con el vigente Plan Estratégico de Ciudadanía e Integración 2011-2014 (aprobado el 23 de septiembre de 2011) que tiene como principal objetivo fortalecer la cohesión social en un nuevo contexto migratorio caracterizado por la reducción de flujos de entrada de inmigrantes. Uno de sus objetivos es reforzar tanto los instrumentos y políticas de integración como los servicios públicos y de participación, para garantizar el acceso de todos los ciudadanos en condiciones de igualdad. No se contemplan, por tanto medidas específicas para los inmigrantes, sino que se reconoce que su integración es uno de los retos más importantes que afronta la sociedad española y un pilar básico de la política integral de inmigración puesta en marcha desde 2004, junto con los consabidos principios de la lucha contra la inmigración irregular, la vinculación de la inmigración legal a las necesidades del mercado de trabajo y la cooperación al desarrollo de los países de origen. Se promueve en definitiva, una transversalidad bidireccional que no es compatible con un mayor desarrollo normativo de la integración contractual y vinculante, sino que más bien aspira a ser la vía soft law de esa finalidad de normalización de la convivencia en una sociedad diversa. Por eso, el Plan recoge, desde un ámbito con menores tensiones normativas, nuevas medidas necesarias para dar respuesta a ciertos retos inmediatos como son la gestión de la diversidad, el fortalecimiento del capital humano y la igualdad de oportunidades para garantizar la cohesión social.

\section{Informes sobre el esfuerzo de integración y control discrecional de las Comunidades Autónomas}

16 El alcance de las reformas estatutarias tiene una incidencia plena no sólo en el desarrollo de la política de integración de los inmigrantes sino también en la regulación de las medidas necesarias al efecto en los ámbitos social, económico y de participación social de los mismos que se incardinan en la situación administrativa de los extranjeros. Respecto a la primera cuestión desde el ámbito regional con anterioridad a las reformas estatutarias ya se habían desarrollado diversas medidas contenidas en los documentos programáticos generales o programas específicos de las Comunidades Autónomas en el ámbito de la sanidad, educación, vivienda, los servicios sociales, las políticas para la paridad o la juventud ${ }^{29}$. Tales políticas de integración regional, con la excepción de Cataluña coinciden cronológicamente con la consolidación de la tercera fase de la construcción de la España inmigrante posterior al año $2000^{30}$. Básicamente, la estructura de los documentos programáticos regionales es similar y establece una concepción integral así como multidimensional de la integración, teniendo presente la cuestión migratoria : acogida, educación, trabajo, formación, salud, vivienda, servicios sociales, sensibilización, cooperación al desarrollo y asistencia jurídica. El alcance es amplio pero no existe homogeneidad en las medidas previstas en los programas de integración autonómica ni en cuanto se refiere a los contenidos ni respecto a las propuestas que se realizan aunque obviamente la proyección sí es sensiblemente 
diferente en aquellas Comunidades autónomas que recientemente han ampliado los campos de intervención en materia de extranjería ${ }^{31}$.

De hecho, tras la atribución expresa de competencias en esta materia a las instituciones autonómicas desde una dimensión multinivel ${ }^{32}$ en el ámbito de la sanidad, educación, alojamiento y los servicios sociales, las políticas para la igualdad y la juventud ${ }^{33}$ se ha dado paso a un estadio más avanzado de propuestas de acogida autonómicas que visibilizan el mayor protagonismo de las Comunidades Autónomas en la acreditación documental de la integración del inmigrante con vistas al cumplimiento de objetivos estatutarios, tales como la integración social, económica, laboral y cultural ${ }^{34}$. En el caso de la Comunidad Valenciana, la Ley 15/2008, de 5 de diciembre, de la Generalitat, de Integración de las Personas Inmigrantes en la Comunidad Valenciana ${ }^{35}$; Decreto 93/2009, de 10 de julio, por el que se aprueba el Reglamento de la Ley 15/2008, de 5 de diciembre, de la Generalitat, de Integración de las Personas Inmigrantes ${ }^{36}$; y en Cataluña la Ley 10/ 2010, de 7 de mayo, de acogida de las personas inmigradas y de las regresadas a Cataluña ${ }^{37}$.

Desde esta mayor proyección práctica y reconocimiento formal del rol de las Comunidades autonómicas en la coordinación de las políticas de integración se puede presentar la adaptación autonómica de los llamados informes sobre esfuerzo de integración fijados y pautados por la Instrucción DGI/SGRJ/8/2011 de aplicación del Reglamento de la Ley orgánica $4 / 2000$, derogada desde primeros de julio 2012. Con anterioridad sólo instrumentos como el padrón municipal o la institución del arraigo han operado como cauces para percibir prestaciones de la administración local y para posibilitar una intervención decidida de los Ayuntamientos en la atención la población inmigrada. Si bien la praxis administrativa de las diferentes Comunidades autonómicas cuenta por el momento desde febrero de 2012 con un breve recorrido temporal, ello no ha sido óbice para advertir de las primeras disimilitudes o falta de homogeneidad a la hora de certificar el llamado "esfuerzo de integración ». Dentro de su contenido mínimo, el informe tendrá la certificación, en su caso, de la participación activa del extranjero en acciones formativas destinadas al conocimiento y respeto de los valores constitucionales de España, los valores estatutarios de la Comunidad Autónoma en que se resida, los valores de la Unión Europea, los derechos humanos, las libertades públicas, la democracia, la tolerancia y la igualdad entre mujeres y hombres, así como el aprendizaje de las lenguas oficiales del lugar de residencia señalando expresamente el tiempo de formación dedicado a los ámbitos señalados. Para ello, nada obsta que se tendrán en consideración las acciones formativas desarrolladas por entidades privadas debidamente acreditadas o por entidades públicas.

Así adquiere el margen de intervención autonómico una significación importante en la medida en que puede dar paso a variantes en la forma de ordenar los extremos del informe en cuanto a su contenido y formalización. De hecho, hay Comunidades autónomas que podrían agruparse en una misma fórmula acreditativa o presentan programas propios no sólo de esfuerzo de integración sino más bien exigiendo un refuerzo de la integración efectiva por cuanto adolecen de un criterio claro y establecido sobre los contenidos a exigir respecto a la duración y las entidades que pueden impartir los cursos. Son un número muy reducido las autonomías que tienen definidos los contenidos marcados para otorgar el certificado en una normativa propia $^{38}$, por lo que es posible diferenciar dos modalidades. La primera contiene una visión más amplia y en cierto modo holística valorando otros aspectos formativos, 
educativos y de participación mientras que la segunda tiene cierta tendencia a ceñirse exclusivamente a los contenidos marcados a nivel estatal ajustándolos básicamente a aspectos legales y culturales propios o adicionales. De modo sumario, a continuación se expondrán las diferentes modalidades que hacen operativo, pese a su dudosa efectividad, el informe sobre el esfuerzo de integración :

\subsection{Modalidad de acreditación holística y/o abierta con puntos de inflexión}

20 La Comunidad de Aragón no tiene una regulación propia por lo que se admite una forma amplia de acreditar el esfuerzo de integración de aquellas personas que hayan participado en acciones formativas dedicadas a la ampliación del conocimiento y respeto de los valores constitucionales, los derechos humanos y las libertades públicas, el sistema y los principios democráticos así como el aprendizaje de las lenguas oficiales en la Comunidad Autónoma de Aragón. En concreto, para ello siguiendo la base de la Instrucción admite la posible concurrencia de otras acciones formativas tendentes a la ampliación de conocimientos personales y su implicación activa en la vida social. Aunque nada especifica sobre el procedimiento de acreditación de las entidades públicas o privadas que deben impartir la formación. Sólo se fijan dos extremos que atañen más al modus acreditativo y menos al contenido stricto sensu. Las certificaciones deben hacer constar el número de horas de la acción formativa, el contenido de las mismas y el porcentaje de asistencia. La validez de su expedición será de tres meses anteriores al procedimiento por el que se solicite presentar el informe.

21 En una línea pareja, sin duda el referente vasco es aquel que postula un marco más gradual de acreditación del esfuerzo de integración en la medida en que se tienen en cuenta de modo global los diferentes ámbitos que inciden en el proceso de integración. Esto es una suerte de background o historial del proceso de integración, interesante por cuanto no da cuenta de un único elemento de prueba sino más bien indaga sobre el recorrido de integración del inmigrante en la sociedad vasca. Admite un amplio abanico de prueba o acreditación de su esfuerzo de integración, fijando más que ámbitos, sugerencias o guías para facilitar la acreditación. Es menos determinista puesto que no fija una prueba o programa propio sino que presenta las diferentes posibilidades agrupándolas en varios ámbitos orientativos, corroborando así la complejidad del proceso bidireccional de integración con más elementos valorativos o aclaratorios existentes o preexistentes a la residencia en el territorio de acogida.

De este modo, en el apartado correspondiente al ámbito formativo se admite la certificación acreditativa de estar cursando o haber finalizado alguna titulación de carácter oficial del sistema educativo ${ }^{39}$. Así como, la certificación acreditativa de haber cursado o estar cursando formación para el empleo y otro tipo de acciones destinadas al conocimiento y respeto de los valores requeridos en los términos de la Instrucción. Como aporte original, se combinan con el ámbito de participación, la certificación de pertenencia o participación en asociaciones privadas sin ánimo de lucro u otro tipo de organizaciones de carácter social debidamente registradas así como la afiliación a sindicatos o a partidos políticos sin duda un indicador del grado de compromiso social en la sociedad de acogida. De modo más genérico, incluye también el certificado de participación en eventos sociales, culturales o de cualquier tipo que pueda promover la plena integración de las personas extranjeras en la sociedad $u$ otro tipo de documentos 
que puedan acreditar, a juicio de la persona solicitante, un esfuerzo de integración en el ámbito de la participación. E, incluso se tienen en cuenta el ámbito de inclusión social, laboral así como la búsqueda de empleo o en su caso la solicitud de nacionalidad española y residencia o certificado de empadronamiento ${ }^{40}$.

Dentro de esta modalidad amplia de acreditación del esfuerzo de integración la Comunidad Andalucía es un caso excepcional en la regulación autonómica del procedimiento del esfuerzo de integración. En el mismo sentido propuesto por el artículo 62.1 del Estatuto Andaluz se recoge como objetivo prioritario « la competencia exclusiva en las políticas de integración social, económica, laboral y cultural de los inmigrantes en Andalucía ». De hecho en la Orden de 16 de febrero de 2012, por la que establece el procedimiento para la emisión del informe sobre esfuerzo de integración de la persona extranjera en el ámbito de la Comunidad Autónoma de Andalucía ${ }^{41}$ se contienen aspectos de remisión a la ya drogada Instrucción DGI/SGRJ/8/2011, junto con otros que complementan y gestionan el procedimiento a seguir para la acreditación de modo ordenado.

Por ello, sin duda constituye el ámbito mayormente desarrollado con aspectos de mejora respecto al modus integrandi seguido en la misma modalidad por otras autonomías, en la medida que no sólo imprime el carácter propio en la valoración mínima exigida ${ }^{42}$ sino que abre una válvula de escape a otros méritos complementarios para ser incluidos en el informe respectivo. Por ejemplo, la pertenencia a asociaciones y entidades sociales y culturales, organizaciones sindicales o empresariales con implantación en Andalucía, o ejercer el voluntariado en entidades reconocidas como tales, todo ello en el territorio donde resida la persona solicitante.

Tales aspectos de mejora no sólo afectan al contenido sino también a aspectos de forma como los órganos competentes para tramitar y resolver como expresamente determinados en el artículo 9. Esto es, se delega la competencia de la tramitación inicial de las solicitudes en las personas titulares de las Delegaciones Provinciales de la Consejería de Empleo mientras que recae la resolución y emisión del informe regulado en la presente Orden en la persona titular de la Dirección General competente en materia de Coordinación de Políticas Migratorias.

En cambio, respecto a los extremos de la tramitación en el artículo 10 se detalla el iter administrativo una vez recibidas las solicitudes. El órgano competente para tramitar procederá a la comprobación del cumplimiento de los requisitos por parte de los solicitantes y que los contenidos de los documentos aportados coincidan con los méritos alegados en la solicitud. A la vista de los requisitos y documentos aportados, el órgano competente en el caso de solicitudes admitidas a trámite las remitirá inmediatamente a la Comisión de Valoración, que se constituye según el artículo 11 por la Dirección General competente en materia de Coordinación de Políticas Migratorias por tres personas funcionarias pertenecientes a la referida Dirección General y presidida por una de ellas con nivel de Jefatura de Servicio.

27 La Comisión de Valoración como órgano evaluador expresamente reconocible ex lege podrá realizar cuantas actuaciones estime necesarias para la determinación, conocimiento y comprobación de los datos en virtud de los cuales se realizará la correspondiente propuesta. A tal efecto podrá requerir a la persona interesada para que aporte la documentación complementaria que permita realizar adecuadamente la valoración. El plazo para presentar dicha documentación será de diez días hábiles. Y, de igual modo, podrá realizar cuantas verificaciones o controles considere oportunos al 
mismo fin. Transcurrido el plazo de tres meses podrán entenderse desestimadas por silencio administrativo aquellas solicitudes presentadas sobre las que no se haya emitido y notificado informe positivo, sin perjuicio del cumplimiento de la obligación legal de resolver.

En el momento de emisión del informe, conforme al artículo 12 en el supuesto de que la persona interesada cumpla los requisitos y su participación activa en acciones formativas haya sido valorada favorablemente, el órgano competente emitirá el correspondiente informe positivo sobre esfuerzo de integración con los datos personales, la participación activa en las acciones formativas, las entidades públicas y privadas debidamente acreditadas, el número de horas que haya destinado a ellas y su cómputo global. En caso contrario, si la solicitud no obtuviera la suficiente puntuación para ser valorada favorablemente, el órgano competente resolverá denegando la petición.

Respecto al contenido sustantivo del informe, al igual que ocurre en la variante del País Vasco se valida la carga probatoria de otras enseñanzas que pueden servir para demostrar la participación activa en las acciones formativas y que en términos lógicos para supuestos de renovación de residencia, sí pueden dar cuenta de un esfuerzo no sólo puntual sino gradual en la integración. Por este motivo, podrán admitirse para su valoración, aunque no se haya superado las pruebas, la asistencia regular a las enseñanzas correspondientes al Sistema Educativo Español, contempladas en la Ley Orgánica 2/2006, de 3 de mayo, de Educación. Nuevamente, tendrá especial consideración la Educación de personas adultas, impartida por los Centros de Adultos dependientes de entidades públicas o acreditadas al efecto. Las acciones de Formación Profesional para el Empleo impartidas por los Servicios Públicos de Empleo o por otros organismos públicos o entidades acreditadas por los mismos. También la asistencia a cursos de lengua y cultura española y otros valores impartidos por entidades públicas, o por entidades privadas acreditadas. Aunque a modo de cláusula abierta, son admisibles la asistencia a jornadas, congresos, cursos y otras actividades formativas impartidos por entidades públicas o por entidades privadas acreditadas, conforme a lo dispuesto en la Disposición transitoria única.

En otro orden de cosas, dentro de la misma modalidad se podría englobar salvo por la variante idiomática, la tramitación del informe sobre el esfuerzo de integración en cinco comunidades autónomas : Canarias, Extremadura, Castilla la Mancha, La Rioja y Cataluña. De hecho, con la excepción del caso catalán, el resto no distan en exceso de los mínimos marcados por la Dirección General de Inmigración. El referente catalán desde los primeros Planes de integración trata de articular una vía catalana de integración que consiga un máximo equilibrio entre el respeto a la identidad con la asunción de los valores democráticos y los elementos culturales de la sociedad catalana. Todo ello, sin necesidad de renunciar o infravalorar su cultura e identidad de origen. A tal efecto se combinan diversas estrategias a nivel programático desde 1993 con los Planes de Ciudadanía e Inmigración hasta el Pacto por la Inmigración 2008 hasta una articulación jurídica progresiva de los Decretos 188/2001 y 252/2004 sobre derechos de los extranjeros y su escolarización hasta la Ley de acogida. Así, en lo tocante a informar sobre el grado de integración especifica el órgano encargado de emitir el informe del Departamento de Bienestar Social y Familia, es la Dirección general para la inmigración ${ }^{43}$. Tienen prioridad la participación activa en acciones formativas destinadas al conocimiento y respeto de los valores constitucionales, de los valores 
estatutarios de Cataluña, de los valores de la Unión europea, de los derechos humanos, las libertades públicas, la democracia, la tolerancia o la igualdad entre hombres y mujeres, del seguimiento de programas de inserción cultural (conocimiento de la sociedad catalana), de los conocimientos suficientes de la lengua catalana y castellana o la colaboración con las redes sociales. Aunque también admite a falta de desarrollo reglamentario de la Ley de acogida cualquier documento determinante de su integración social sin perjuicio de realizar una entrevista personal corroborando la documentación original sobre los programas de inserción socio-laborales y culturales desarrollados, requiriendo un mínimo de uno, así como conocimientos lingüísticos de las dos lenguas oficiales con un mínimo de nivel A 2 en ambos casos puesto que salvo dificultades del aprendizaje por situaciones de analfabetismo, discapacidad y similares puede conllevar la emisión de un informe desfavorable.

31 En última instancia, entre aquellas Comunidades autónomas que si bien siguen fielmente los contenidos mínimos del informe sobre el esfuerzo de integración cabe también trazar un eje común probatorio adicional : la entrevista presencial. Es el caso de la comunidad de Navarra que expresamente indica que para la elaboración del informe será necesaria una entrevista presencial con la persona solicitante realizada por el personal técnico competente en la elaboración del mismo. Aunque esta entrevista podrá ser sustituida por la cumplimentación y envío de un informe realizado por personal técnico de entidades públicas y/o privadas que han desarrollado algún tipo de intervención social con la persona solicitante, siempre a criterio de la Oficina de Atención a la Inmigración. Sólo en casos excepcionales que no se especifican y a criterio de la Oficina de Atención a la Inmigración se podrá elaborar el informe con la documentación aportada por la persona solicitante, omitiendo la entrevista personal. También sigue esta misma dinámica procedimental en la Comunidad Autónoma de Castilla y León, competente aunque si determina a diferencia de sus homólogos el órgano competente para emitir los informes de esfuerzo de integración es la Dirección General de Relaciones Institucionales y Acción Exterior de la Consejería de la Presidencia, a tenor de los dispuesto en el Decreto 32/2011, de 7 de julio, por el que se establece la estructura orgánica de la Consejería de la Presidencia ${ }^{44}$. Únicamente se emitirán informes positivos de esfuerzo de integración por lo que cuando no sea posible la emisión de este informe positivo, se comunicará al interesado tal imposibilidad; sin que ello suponga constituir un informe negativo o desfavorable de integración. Será suficiente, a efectos de emisión del informe, que la acreditación de las acciones realizadas se circunscriba al periodo de la vigencia de la autorización de residencia o de residencia y trabajo que caduca, y que pretende renovar. No obstante, si las acciones formativas realizadas en dicho periodo resultan insuficientes, se podrá hacer constar en el informe aquéllas realizadas con anterioridad. El informe tendrá en consideración las acciones formativas desarrolladas por entidades privadas acreditadas o por entidades públicas sin distingos ulteriores con una validez de tres meses a partir de su fecha de emisión.

No obstante, al constituir un contenido mínimo, se podrá complementar con la acreditación de acciones formativas en otros ámbitos que se hayan realizado para la comprensión de la sociedad castellana y leonesa así como española. Por ejemplo, servicios de colaboración y ayuda con entidades públicas o entidades privadas sin ánimo de lucro o de carácter social, que pongan de manifiesto la integración del interesado mediante la labor desarrollada. A este respecto, se tendrán en consideración la participación en programas de integración que hayan obtenido subvención de las 
Administraciones Públicas. Las asistencias ocasionales o puntuales a charlas, conferencias, jornadas, encuentros, etc, que no formen parte de un programa con un itinerario formativo definido y completo, se podrán valorar en última instancia. Por tanto, el recurso a la entrevista es potestativo «se podrá celebrar entrevista con el interesado", a efectos de verificar personalmente el grado de integración social y cultural así como poder apreciar en su conjunto los aspectos certificados en los distintos ámbitos.

\subsection{Modalidad(es) de acreditación cerrada en base a un programa propio}

Dentro de esta modalidad, es posible identificar tres modelos con diferentes niveles o intensidades de acreditación. En base a la titularidad competencial reconocida en el artículo 10.3 in fine del Estatuto de autonomía «la actuación de la Generalitat se centrará en los derechos y atención social de los inmigrantes y en el artículo 59.5 se señala la colaboración en lo referente a las políticas de inmigración ». Bajo este marco competencial, la Comunidad Valenciana fija uno de los primeros marcos legislativos definitorios del compromiso de integración por medio de la Ley 15/2008, de 5 de diciembre, de la Generalitat, de Integración de las Personas Inmigrantes en la Comunidad Valenciana ${ }^{45}$ y el Decreto 93/2009, de 10 de julio, del Consell, por el que se aprueba el Reglamento de la Ley 15/2008, de 5 de diciembre ${ }^{46}$. Sin duda la Comunidad Valenciana se anticipa al desarrollo reglamentario a nivel estatal y a los mínimos marcados por la ya derogada Instrucción DGI/SGRJ/8/2011 presentando una fórmula acreditativa propia y voluntaria que certifica el denominado compromiso de integración. La opción integrada comporta la participación activa al Programa Voluntario de Comprensión de la Sociedad Valenciana Escuela de Acogida ${ }^{47}$, si bien no hace más que matizar un modus operandi propio sin perjuicio de otras acciones formativas destinadas al conocimiento y respeto de los valores requeridos de modo redundante en la normativa de extranjería. Así, junto a una controvertida seguridad jurídica en línea de tendencia es restrictivo en cuanto sólo se valida un certificado emitido dentro el programa, esto es el certificado de aprovechamiento del Programa Voluntario de Comprensión de la Sociedad Valenciana Escuela de Acogida que integra información y formación sobre competencias lingüísticas básicas, legislación social y laboral así como orientación para el acceso al empleo, instituciones de autogobierno, derechos y obligaciones e información sobre los servicios que las Administraciones públicas para la plena integración de las personas inmigrantes..

Este aspecto pese a la voluntariedad refrendada en la ley valenciana puede añadir obligaciones que podrían dificultar el acceso a la regularidad en el territorio autonómico. Y, por lo que respecta al control de la expedición del certificado del curso del Programa Voluntario de Comprensión de la Sociedad Valenciana, el rol de las Escuelas de acogida es determinante sobre las entidades que pueden incorporarse ${ }^{48}$ junto a las funciones de las Agencias de Mediación para la integración y la Convivencia Social (AMICS) y el Foro Valenciano de la Inmigración, el Observatorio de la Inmigración y otros que se creen con carácter permanente o temporal.

De hecho, la definición de los contenidos opera por remisión a los establecidos para el programa voluntario de comprensión de la sociedad valenciana en el artículo 6 del Decreto 93/2009, de 10 de julio que en otros extremos detallan un régimen de gratuidad 
para las personas inmigrantes asistentes a los mismos y con medios materiales adecuados para proporcionar las actividades contenidas en el programa Escuela de Acogida. Una duración mínima de 40 horas lectivas en clases de 20 a 40 alumnos mayores de 18 años impartidos por diplomados o licenciados sin remuneración alguna en aquellas especialidades que tengan relación con las materias.

En un línea de tendencia común pero menos sofisticada y con posterioridad a las bases de la Instrucción general, la Dirección General de la Comunidad de Madrid por medio de una nota informativa determina una modalidad cerrada como singularidad propia que incluye la asistencia gratuita a un Programa propio "Conoce tus leyes ${ }^{49}$ a cargo de los Centros de Participación e integración de inmigrantes y exclusivamente en el caso de no hispano-hablantes cursos de conocimiento de español básico.

Por último, si bien la Comunidad de Baleares en base al artículo 30.50 del Estatuto reconoce su competencia exclusiva en la «integración social y económica del inmigrante " propone una modalidad intermedia sobre el esfuerzo de integración próxima tanto a la modalidad abierta como cerrada en su reciente Instrucción $1 / 2013^{50}$. Básicamente porque establece una fórmula opcional integrada bien por acciones formativas privadas o públicas o bien eventualmente por la evaluación de un Plan formativo muy detallado en cuanto a contenidos evaluables, temarios, horas, etc y lugar donde realizar las pruebas ${ }^{51}$. En caso de no poder acreditar la participación en las acciones formativas de entidades públicas o privadas, la Dirección General de Cooperación e Inmigración de Baleares ha desarrollado un programa de formación, con su contenido, fases y duración, así como el sistema de ejecución y participación de las personas inmigrantes, para que la persona interesada pueda obtener un certificado una vez superada satisfactoriamente la prueba evaluadora final del Plan. Este programa formativo está destinado al conocimiento y respeto de los valores constitucionales de España, los valores estatutarios de la Comunidad Autónoma de las Islas Baleares, los valores de la Unión europea, los derechos humanos, las libertades públicas, la democracia, la tolerancia y la igualdad entre mujeres y hombres, así como el aprendizaje de las lenguas oficiales de la Comunidad Autónoma de las Islas Baleares, además de aquellas otras acciones formativas destinadas a favorecer la integración del extranjero.

\section{Algunas reflexiones valorativas}

La nota común que aflora en la aplicación de las medidas de integración es el normativismo y extensionismo de unos parámetros casi idénticos sobre el inmigrante admisible o querido en el contexto europeo que salva importantes márgenes de apreciación por parte de los Estados. Si bien, es cierto que España con el informe sobre el esfuerzo de integración se distancia por el momento de la tendencia hard law de algunos países que han impulsado desde sus respectivas normativas nacionales programas de integración de carácter jurídicamente vinculante. El modelo español apuesta actualmente por un concepto de integración muy reducido que sin embargo desafortunadamente en nada recuerda a la bidireccionalidad de la que se habla desde la Unión Europea. Más bien en línea de tendencia es un mero espejismo.

39 El pragmatismo meridional que ha caracterizado países como España dada su relativamente reciente concepción como país de destino ha supuesto una articulación normativa acelerada en ciertos casos incluso dubitativa sobre el impacto de las medidas 
o directrices europeas sobre la integración. Una especie de lógica de medidas más subies que realmente choisies por las circunstancias pero que ha significado bajo mi punto de vista igual número de ventajas y desventajas en la proyección normativa de la integración en España desde una perspectiva comparada por imitación y cómodamente expuesta a la voluntad de laissez faire. Máxime si hay extranjeros ajenos a estas medidas de integración que no se ven afectados por estos contratos (como los trabajadores altamente cualificados o aquellos que se beneficien de regímenes jurídicos especiales). o, incluso por la pasividad de transformaciones orientadas por el legislador con ánimo de suplir por medio de la burocratización y la dilación del procedimiento ciertos mecanismos administrativos de contención o control de los derechos que revierten negativamente en su protección. Una cuestión de fondo que subyace en la Instrucción SGIE/2/2012 que deroga la Instrucción DGI/SGRJ/8/2011 que plantea la falta de efectividad « por no haber contribuido a los objetivos de clarificación y homogeneidad en la aplicación de la figura jurídica que se refiere».

El marco normativo de extranjería español prevé así con la emisión de informes dar forma, quizás provisionalmente, a los conceptos jurídicos indeterminados que proliferan en la ley para articular el eje de las políticas de integración. Una cuestión de fondo pendiente como subyace en la Instrucción SGIE/2/2012 que deroga la Instrucción DGI/SGRJ/8/2011 que plantea la falta de efectividad " por no haber contribuido a los objetivos de clarificación y homogeneidad en la aplicación de la figura jurídica que se refiere ». De hecho, la finalidad perseguida parece obviar como la concreción de cada uno de ellos puede da lugar a disimilitud y cierta inseguridad jurídica por su vinculación con la protección o acceso a ciertos derechos o necesidades básicas. Los programas de integración como obligación jurídica con independencia de sus intensidades o adaptaciones se pueden considerar a largo plazo como un retorno a la " asimilación integracionista ", puesto que inciden especialmente en la adquisición de competencias lingüísticas y de carácter cívico. Este esfuerzo añadido que se requiere al inmigrante no va aparejado de una mayor inserción o promoción en atención a sus circunstancias específicas en el mercado laboral sino que visibiliza si cabe más el declive de la capacidad inclusiva del Estado del Bienestar europeo ${ }^{52}$.

Entre las críticas recibidas por estas políticas podríamos trasladar al caso español algunas de los apuntados por Guiraudon y Carrera $^{53}$ :

i. Asimetría de posiciones que no deja espacio para la negociación, sino más bien para la imposición unilateral de condiciones bajo las que nacen las obligaciones ;

ii. Los cursos de idiomas y/o de civismo integrados en sus distintas modalidades no son sensibles a la realidad de las diferentes necesidades y perspectivas en el momento de su llegada ;

iii. Se pauta un concepto muy restringido de la integración no interpretado en clave bidireccional, sino que responde a una concepción unilateral de la misma ;

iv. Tampoco plantea la integración como un proceso en el que la sociedad de acogida que no desempeña ningún papel en esforzarse a acoger a los inmigrantes ;

v. Se establece un tratamiento desigual de los que están exentos (ciudadanos de la UE y, a menudo, trabajadores altamente cualificados o inmigrantes de la OCDE), lo cual refuerza la idea de que sólo algunos inmigrantes necesitan integrarse o tienen dificultades para hacerlo;

vi. El éxito de la integración se reducirá a los indicadores cuantitativos de las tasas de éxito de los exámenes de civismo e idioma y el número de informes favorables ; 
vii. Las normas de extranjería, el eje vertebrador de las transformaciones de la integración no aportan una definición precisa y clara de la integración cívica, conforme y adecuada al principio de legalidad. La ley debe ser lo más objetiva posible pero la categoría de valores es excesivamente vaga y subjetiva dando pie a interpretaciones e ideologías divergentes.

En cualquier caso, con independencia de los grados o intensidades, tales legítimas e injustas (materialmente) construcciones de integración desde el principio de soberanía estatal tienen plena incidencia tal y como apunta Habermas ${ }^{54}$ sobre las cuestiones éticopolíticas. Unas cuestiones que pueden redundar negativamente en la igualdad en derechos de los grupos discriminados que difícilmente pueden reconocerse como sujetos de derechos sino más bien como meros objetos de obediencia sumisa sin capacidad de negociación sobre la forma y condiciones de integrarse.

\section{BIBLIOGRAFÍA}

AÑóN ROIG María José, « Igualdad y especialidad en el procedimiento administrativo de extranjería », Cuadernos electrónicos de Filosofía del Derecho, nํ14, 2006, p. 1-20.

«Integración: una cuestión de derechos ", Arbor: Políticas migratorias y sociedad integrada, vol. 186, no 744, 2010, pp. 625-638.

BERTOSSI Christophe « National models of integration in Europe: A comparative and critical perspective » American Behavioral Scientist 55(12), 2011, pp. 1541-1561.

BLÁZQUEZ RODRÍGUEZ Irene, Regiones, Unión Europea e integración de los inmigrantes. Una perspectiva desde el Derecho Comparado, Barcelona, Atelier, 2008,172 p.

BONINO COVAS Carla ; ARAGÓN MEDINA, Jorge y ROCHA SÁNCHEZ, Fernando, Los planes de las Comunidades Autónomas para la integración social de las personas inmigrantes, Madrid, CCOO, 2003, 196 p.

CACHÓN Lorenzo, « La integración de y con los inmigrantes en España : debates teóricos, políticas y diversidad territorial », Política y Sociedad 45 (1), 2008, pp. 205-35.

(coord.) Inmigración y conflictos en Europa. Aprender para una mejor convivencia, Barcelona, Editorial Hacer, 2011, 504 p.

CARRERA Sergio, « Programas de integración para inmigrantes en perspectiva comparada en la Unión Europea », Migraciones, núm. 20, 2006, pp. 37-73.

In search of the perfect citizen?: the intersection between integration, immigration, and nationality in the EU, Leiden, Boston, Martinus Nijhoff Publishers, 2009, 528 p.

CARRERA Sergio \& WIESBROCK Anja, Civic Integration of Third-Country Nationals. Nation-alism versus Europeanisation in the Common EU Immigration Policy, www.ceps.eu, 2009.

COURNIL Christel ; DEPIGNY Yves, « Contractualisation et externalisation de la politique migratoire : analyse et critique de la loi Hortefeux », Revue de droit public, no. 4, 2008, pp. 1045-1079. 
DE LUCAS MARTÍN Javier, « Ciudadanía : la jaula de hierro para la integración de los inmigrantes », AUBARELL SOLDUGA Gema y ZAPATA-BARRERO Ricardo (ed.) Inmigración y procesos de cambio. Europa y el mediterráneo en el contexto global, Barcelona, Icaria, 2004, pp. 215-236.

«La integración de los inmigrantes, la integración política, condición del modelo de integración », DE LUCAS Javier y DÍEZ BUESO Laura, La integración de los inmigrantes, Madrid, Centro de estudios Políticos y Constitucionales, 2006, pp. 11-43.

«Sobre los fundamentos de la igualdad y del reconocimiento. Un análisis crítico de las condiciones de las políticas europeas de integración ante la inmigración »,VVAA. Inmigración e integración en la UE. Dos retos para el siglo XXI, Eurobask, Bilbao, 2012, pp. 11-92.

FIERI (Forum Internazionale ed Europeo di Ricerche sull'Immigrazione) a cura di CAPONIO Tiziana ; PASTORE Ferrucio, Dall'ammisione all'inclusione : verso un approccio integrato ? Un percorso di approfondimento comparativo a partire da alcune recenti esperienze europee, Consiglio nazionale de l'economia e del lavoro, Ministero del Lavoro e delle Politiche Sociali - Direzione Generale dell'immigrazione e delle politiche di integrazione, Roma, 2012, pp. 1-77.

GUIRAUDON Virginie, «Contratos de integración para inmigrantes : tendencias comunes y diferencias en la experiencia europea ", Área : Demografía, Población y Migraciones Internacionales Real Instituto ElCano, ARI 43/ 2008.

HABERMAS Jürgen, La inclusión del otro. Traducción y estudio preliminar J.C. Velasco, Barcelona, Paidós, 1999, 258 p.

ILLAMOLA Mariona « Los principios comunes como marco de la política de integración de inmigrantes de la Unión Europea y su incorporación a la política española de inmigración », Revista de Derecho comunitario europeo, ํㅡ 38, 2008, pp. 155-182.

KOOPMANS Ruud, « Trade-offs between equality and difference: Immigrant, integration, multiculturalismo and the Welfare State in cross-national perspective ", Journal of Ethnic and Migration Studies, vol. 36, no 1, 2010, pp. 1-26.

LOCHACK Danièle, «L'intégration comme injonction. Enjeux idéologiques et politiques liés à l'immigration », Cultures et conflits, $\mathrm{n}^{\circ}$ 64, 2006, pp. 131-147.

MARTÍNEZ DE LIZARONDA ARTOLA Antonio, « La integración de los migrantes en España : el modelo Patchwork », Revista Migraciones, № 26, 2009, pp. 115-146.

MONTILLA MARTOS José Antonio «Las competencias autonómicas en inmigración tras la STC 31/2010 », Revista d'Estudis Autnòmics i federals, n. 14, 2011, pp. 152-185

MORENO FUENTES Francisco Javier, Inmigración y bienestar en España, Barcelona, Obra Social La Caixa, 2011, 205 p.

MOYA MALAPEIRA David, « Los informes municipales de arraigo social y disponibilidad de vivienda adecuada expedidos a los extranjeros extracomunitarios : el papel de Cataluña en la Oficina del Padrón Municipal », Cuadernos de Derecho Local, 17, 2008, pp. 134-151.

NIESSEN Jan; HUDDLESTON Thomas, Legal frameworks for the integration of third-country nationals, Leiden, Martinus Nijhoff, 2009, 245 p.

PASCOUAU, Yves \& STRIK, Martina Hermina Antonia (Ed.), Which Integration Policies for Migrants? Interaction between the EU and its member states, Nijmegen, Wolf Legal Publishers.

SANTOLAYA MACHETTI Pablo, «Extranjería y nuevos Estatutos de Autonomía », Revista d'Estudis Autonòmics i Federals, núm. 4, 2007, pp. 159-181. 
SOLANES CORELLA Ángeles « ¿Integrando por ley ? De los contratos europeos de integración al compromiso de la ley autonómica Valenciana 15/2008 », Revista española de derecho de extranjería y migratorio, 20, 2009, pp. 47-77.

« Un balance tras 25 años de leyes de extranjería en España : 1985-2010 », Revista del Ministerio de Trabajo e Inmigración, 90, 2010, pp. 77-101.

«El buen inmigrante: regular e integrado », REDUR 9, diciembre, 2011, pp. 99-125.

« Human rights and Conflicts in European Multicultural societies », Migraciones Internacionales, vol. 7, núm. 1, 2013, pp. 70-100.

SOLÉ PUIG Carlota ; IZQUIERDO ESCRIBANO Antonio, Integraciones diferenciadas : migraciones en Cataluña, Galícia y Andalucía, Barcelona, Anthropos, 2005, 364 p.

VAN OERS Ricky; ERSBøLL Eva; KOSTAKOPOULOU Dora, A Definition of belonging: Language and integration tests in Europe, Leiden, Martinus Nijhoff, 2010, 338 p.

TRIADAFILOPOULOS Triadafilos, « Illiberal means to liberal ends? Understanding recent immigrant integration policies in Europe ", Journal of Ethnic and migration Studies, vol. 37, no 6, 2011, pp. 861-880.

\section{NOTAS}

1. Pacto europeo de inmigración y asilo, Bruselas 16 de septiembre 2008, no 13189/08 ASIM 68, Programa de Estocolmo- Una Europa abierta y segura que sirva y proteja al ciudadano (DOUE 2010/C 115/01) ap. 6.1. Vid. entre otros COM (2000) 757 final, de 22 de noviembre, Comunicación de la Comisión al Consejo y al Parlamento Europeo sobre una política comunitaria de inmigración. Reiterada, por ejemplo, en COM (2001) 387 final, de 11 de julio, Comunicación de la Comisión al Consejo y al Parlamento Europeo relativa a un método abierto de coordinación de la política comunitaria en materia de inmigración y COM (2003) 336 final, de 3 de junio, Comunicación de la Comisión al Consejo, al Parlamento Europeo, al Comité Económico y Social Europeo y al Comité de la Regiones, sobre inmigración, integración y empleo. Comunicación de la Comisión, Programa de la Haya: diez prioridades para los próximos cinco años. Una asociación para la renovación europea en el ámbito de la libertad, la seguridad y la justicia, COM (2005) 184 final de 10.5.2005. Cfr. El programa de La Haya: consolidación de la libertad, la seguridad y la justicia en la Unión Europea (2005/C 53/01), Diario Oficial C 53 de 3.3.2006. Y, más recientemente, COM (2011) 455 final, de 20 de julio de 2011, Comunicación de la Comisión al Parlamento europeo, al Consejo, al Comité Económico y Social Europeo y al Comité de las Regiones «Agenda Europea para la Integración de los Nacionales de Terceros Países COM (2012) 250 final, de 30 de mayo de 2012, Comunicación de la Comisión al Parlamento Europeo y al Consejo, III Informe Anual sobre Inmigración y Asilo (2011) así como el último IV Informe Anual sobre Inmigración y asilo 2012, COM (2013) 422 final, Comunicación de la Comisión al Parlamento Europeo y al Consejo, de 17 junio de 2013.

2. SOLANES CORELLA Ángeles, "El buen inmigrante: regular e integrado», REDUR 9, diciembre, pp. 99-125, p. 86.

3. DE LUCAS Javier, «Sobre los fundamentos de la igualdad y del reconocimiento. Un análisis crítico de las condiciones de las políticas europeas de integración ante la inmigración», VVAA. Inmigración e integración en la UE. Dos retos para el siglo XXI, Eurobask, Bilbao, 2012, pp. 11-92, p.123, ILLAMOLA Mariona, «Los principios comunes como marco de la política de integración de inmigrantes de la Unión Europea y su incorporación a la política española de inmigración», Revista de Derecho comunitario europeo, no 38, 2008 pp. 155-182, p. 165. 
4. PASCOUAU Yves \& STRIK Martina Hermina Antonia. (Ed.), Which Integration Policies for Migrants? Interaction between the EU and its member states, Nijmegen,Wolf Legal Publishers, vid. p. 3-14.

5. BERTOSSI Christophe, « National models of integration in Europe: A comparative and critical perspective», American Behavioral Scientist 55(12), 2011, pp. 1541-1561.

6. DE LUCAS Javier, «Sobre los fundamentos de la igualdad y del reconocimiento. Un análisis crítico de las condiciones de las políticas europeas de integración ante la inmigración», VVAA. Inmigración e integración en la UE. Dos retos para el siglo XXI, Eurobask, Bilbao, 2012, pp. 11-92, p. 128; LOCHACK Danièle, «L'intégration comme injonction. Enjeux idéologiques et politiques liés à l'immigration», Cultures et conflits, $\mathrm{n}^{\circ}$ 64, 2006, pp. 131-147.

7. COURNIL Christel; DEPIGNY Yves, «Contractualisation et externalisation de la politique migratoire : analyse et critique de la loi Hortefeux», Revue de droit public, no. 4, 2008, pp. 1045-1079.

8. VAN OERS Ricky; ERSBØLL Eva; KOSTAKOPOULOU Dora, A Definition of belonging: Language and integration tests in Europe, Leiden, Martinus Nijhoff, 2010. TRIADAFILOPOULOS Triadafilos, «Illiberal means to liberal ends? Understanding recent immigrant integration policies in Europe», Journal of Ethnic and migration Studies, vol. 37, nº 6, 2011, pp. 861-880.

9. FIERI (Forum Internazionale ed Europeo di Ricerche sull'Immigrazione) a cura di CAPONIO Tiziana; PASTORE Ferrucio, Dall'ammisione all'inclusione: verso un approccio integrato? Un percorso di approfondimento comparativo a partire da alcune recenti esperienze europee, Consiglio nazionale de l'economia e del lavoro, Ministero del Lavoro e delle Politiche Sociali - Direzione Generale dell'immigrazione e delle politiche di integrazione, Roma, 2012, pp. 1-77.

10. LOCHAK Danièle, «L'intégration comme injonction. Enjeux idéologiques et politiques liés à l'immigration», Cultures et conflits, $\mathrm{n}^{\circ}$ 64, 2006, pp. 131-147.

11. CARRERA Sergio \& WIESBROCK Anja, Civic Integration of Third-Country Nationals. Nation-alism versus Europeanisation in the Common EU Immigration Policy, www.ceps.eu, 2009

12. MARTÍNEZ DE LIZARONDA ARTOLA Antonio, «La integración de los migrantes en España: el modelo Patchwork», Revista Migraciones, ํํ26, 2009, pp.115-146.

13. AÑóN ROIG María José, «Igualdad y especialidad en el procedimiento administrativo de extranjería», Cuadernos electrónicos de Filosofía del Derecho, no 14, 2006, p. 1-20. MOYA MALAPEIRA, David, «Los informes municipales de arraigo social y disponibilidad de vivienda adecuada expedidos a los extranjeros extracomunitarios: el papel de Cataluña en la Oficina del Padrón Municipal» Cuadernos de Derecho Local, 17, pp. 134-151.

14. Algunos ejemplos en la normativa de extranjería sobre la afluencia de informes administrativos. Artículo 9.4 Informe emitido por las autoridades autonómicas competentes para acreditar escolarización, en casos de renovación de autorización y solicitud de residencia de larga duración. Artículo 30.7 informe del esfuerzo de integración que certifica la asistencia a las acciones formativas contempladas en el artículo 2 ter. Art. 35.9 informes de entidades públicas competentes referidos a su esfuerzo de integración, continuidad de formación o estudios, incorporación efectiva o potencial al mercado de trabajo. Art. 68.3 informe arraigo sobre la integración social del extranjero cuyo domicilio habitual se encuentra en su territorio. Periodo de permanencia, vivienda y medios de vida, vínculos con familiares, seguimiento de programas de inserción socio-laborales y culturales. Art. 35.5 informe sobre circunstancias familiares del menor a la representación diplomática del país de origen con carácter previo a la decisión relativa a la iniciación de un procedimiento de repatriación. Art. 68.4 informe sobre afectación al orden público en todos los procedimientos de autorización de residencia o su renovación. Art. 18.2 informe sobre idoneidad de la vivienda, Comunidades Autónomas o ayuntamientos informarán sobre la adecuación de la vivienda a los efectos de la reagrupación familiar.

15. NIESSEN Jan; HUDDLESTON Thomas, Legal frameworks for the integration of third-country nationals, Leiden, Martinus Nijhoff, 2009. 
16. CACHÓN Lorenzo, «La integración de y con los inmigrantes en España: debates teóricos, políticas y diversidad territorial», Política y Sociedad 45 (1), pp. 205-35.

17. MORENO FUENTES Francisco Javier, Inmigración y bienestar en España, Barcelona, Obra Social La Caixa, 2011, p. 13.

18. SOLANES CORELLA Ángeles, «Un balance tras 25 años de leyes de extranjería en España: 1985-2010», Revista del Ministerio de Trabajo e Inmigración, 90, 2010, pp. 77-101, p. 75.

19. Algunos de los objetivos del Plan son: a) eliminación de cualquier tipo de discriminación injustificada de los inmigrantes en el ejercicio de los derechos y deberes en el acceso a los servicios existentes; b) promoción de una convivencia basada en valores democráticos y actitudes tolerantes; c) garantizar una situación legal y social estable; d) combatir las barreras más importantes que dificultan la integración: barrera lingüística, mercado de trabajo y el nivel de calificación y formación; e) lucha contra la explotación laboral de los trabajadores extranjeros; f) la movilización social contra el racismo y la xenofobia.

20. SOLANES CORELLA Ángeles, «Un balance tras 25 años de leyes de extranjería en España: 1985-2010», Revista del Ministerio de Trabajo e Inmigración, 90, 2010, pp. 77-101, p. 75-80.

21. Ley Orgánica $4 / 2000$, de 11 de enero, sobre derechos y libertades de los extranjeros en España y su integración social (BOE $n^{\circ}$ 10, 12/01/2000) modificada por la Ley Orgánica 8/2000, de 22 de diciembre (BOE n. 307 de 23/12/2000), Ley Orgánica 11/2003 de 29 de septiembre (BOE núm. 234 de 30 de septiembre de 2003) y la Ley Orgánica 14/2003, de 20 de noviembre (BOE núm. 279 de 21 de noviembre de 2003).

22. CACHÓN, Lorenzo, (coord.) Inmigración y conflictos en Europa. Aprender para una mejor convivencia, Barcelona, Editorial Hacer, 2011, p. 218. SOLANES CORELLA Ángeles, «Human rights and Conflicts in European Multicultural societies», Migraciones Internacionales, vol. 7, núm. 1, pp. 70-100.

23. Ley Orgánica 2/2009 de 11 de diciembre de 2009 (BOE núm. 299 de 12 de diciembre de 2009). 24. (BOE de 10 de diciembre de 2007) y SSTC 259/2007, de 19 de diciembre de 2007; STC 260/2007; STC 261/2007; STC 262/2007; STC 263/2007; STC 264/2007, y STC 265/2007, todas ellas de 20 de diciembre de 2007, salvo la primera, y publicadas en el BOE de 22 de enero de 2008.

25. DE LUCAS MARTÍN Javier, «Ciudadanía: la jaula de hierro para la integración de los inmigrantes», AUBARELL SOLDUGA Gema y ZAPATA-BARRERO, Ricart (ed.) Inmigración y procesos de cambio. Europa y el mediterráneo en el contexto global, Barcelona, Icaria, 2004, pp. 215-236.

26. AÑóN ROIG María José, «Integración: una cuestión de derechos», Arbor: Políticas migratorias y sociedad integrada, vol. 186, nº 744, 2010, pp. 625-638, p. 635. DE LUCAS MARTÍN Javier, «La integración de los inmigrantes, la integración política, condición del modelo de integración», DE LUCAS, Javier y DÍEZ BUESO Laura, La integración de los inmigrantes, Madrid, Centro de estudios Políticos y Constitucionales, 2006, pp. 11-43

27. Esta Instrucción deroga la DGI/SGRJ/8/2011 de aplicación del Reglamento de la ley orgánica 4/2000 sobre derechos y libertades de los extranjeros en España y su integración social en materia de informes sobre esfuerzo de integración porque no ha contribuido a los objetivos de clarificación y homogeneidad en la aplicación de la figura jurídica que se refiere.

28. Autorización residencia temporal no lucrativa: la no acreditación de la percepción de ingresos periódicos suficientes o tenencia de un patrimonio que garantice la percepción. Autorización residencia temporal por reagrupación familiar: recursos económicos para atender a las necesidades de las familias y la disponibilidad de una vivienda adecuada. Autorización residencia temporal y trabajo por cuenta ajena: no realización de actividad laboral durante un mínimo de 6 meses por año, no acreditar la actividad durante un mínimo de 3 meses por año, situación de alta seguridad social 9 meses de 12 o 18 en un periodo de 24 y la acreditación de recursos económicos y vivienda del cónyuge o pareja de hecho. Autorización de residencia temporal y trabajo por cuenta propia si no quedara acreditada la continuidad en la actividad que dio lugar a autorización de renovación. Real Decreto 557/2011 de 20 de abril (BOE núm. 103 de 30 
de abril). Instrucción DGI/SGRJ/8/2011 de aplicación del Reglamento de la ley orgánica 4/2000 sobre derechos y libertades de los extranjeros en España y su integración social en materia de informes sobre esfuerzo de integración disponible en http://www.intermigra.info/extranjeria/ modules.php?name=News\&file=article\&sid=1939

29. SOLÉ PUIG Carlota; IZQUIERDO ESCRIBANO Antonio, Integraciones diferenciadas: migraciones en Cataluña, Galícia y Andalucía, Barcelona, Anthropos, 2005. BLÁZQUEZ RODRÍGUEZ Irene, Regiones, Unión Europea e integración de los inmigrantes. Una perspectiva desde el Derecho Comparado, Barcelona, Atelier, 2008, pp. 13-42.

30. A día de hoy, son los planes de integración de: Andalucia: a) I Plan integral para la Inmigración en Andalucía 2001-2004; II Plan integral para la Inmigración en Andalucia 2005-2009; Aragón: a) Plan Integral para la inmigración en Aragón; Baleares: a) Plan integral de atención a la inmigración de las Illes Balears 2001-2004; b) II Plan integral de atención a la inmigración de les Illes Balears 2005-2007; Canarias: Plan Canario para la inmigración 2002-2004; II Plan Canario para la inmigración 2005-2006; Cantabria: Plan de interculturalidad 2005; Castilla y León: Plan integral de inmigración en Castilla y León 2005-2009; Castilla La Mancha: Plan regional para la integración laboral de los inmigrantes en Castilla la Mancha; Cataluña: I Plan interdepartamental d'imigració 1993-2000; II Plan interdepartamental d'imigració 2001-2004; Plan de ciutadania i imigració 2005-2008; Madrid: a) Plan regional para la inmigración en la Comunidad de Madrid 2001-2003, b) II Plan regional para la inmigración de la Comunidad de Madrid 2005-2008; Murcia: a) Plan para la integración social de los inmigrantes en la Región de Murcia 2002-2004; II Plan de la integración social de los inmigrantes en la Región de Murcia 2005-2007; Navarra: Plan para la integración social de la población inmigrante 2002-2006; País Vasco: Plan Vasco de inmigración 2003-2005 y La Rioja: I Plan integral de Inmigración La Rioja 2004-2007.

31. Vid. Real Decreto 1463/2009 de 18 de septiembre (BOE núm. 229, 22 de septiembre de 2009 ) sobre traspaso de funciones y servicios a la Generalitat de Cataluña en materia de inmigración: autorizaciones iniciales de trabajo por cuenta propia o ajena

32. SANTOLAYA MACHETTI, Pablo «Extranjería y nuevos Estatutos de Autonomía», Revista d'Estudis Autonòmics i Federals, núm. 4, 2007, pp. 159-181. MONTILLA MARTOS José Antonio «Las competencias autonómicas en inmigración tras la STC 31/2010», Revista d'Estudis Autnòmics $i$ federals, n. 14, pp. 152-185, p. 168. BONINO COVAS Carla; ARAGÓN MEDINA, Jorge y ROCHA SÁNCHEZ, Fernando, Los planes de las Comunidades Autónomas para la integración social de las personas inmigrantes, Madrid, CCOO, 2003.

33. Plan Interdepartamental de Inmigración 1993-2000 y 2001-2004 de la Generalitat de Cataluña, así como el Plan Catalán de Ciudadanía e inmigración (2005-2008), los Planes Canarios de Inmigración 2002-2004 y 2005-2007, los Planes del País Vasco 2003-2005 y 2006-2009, el Plan integral de inmigración de Castilla-León 2005-2009. En Andalucía el I Plan integral para la inmigración (2001-2004) y el II Plan 2006-2009).

34. Estatuto de Autonomía de Cataluña (Ley orgánica 6/2006. BOE núm. 172 de 20 julio 2006), Estatuto de Autonomía de Andalucía (Ley orgánica 2/2007. BOE núm. 68 de 20 marzo 2007), Comunidad Valenciana (Ley orgánica 1/2006. BOE num 8611 abril 2006) Islas Baleares (Ley orgánica 1/2007. BOE núm. 52 de 1 de marzo 2007). Comunidad de Aragón (Ley orgánica 5/2007.BOE núm. 97 de 23 abril 2007).

35. (BOE núm. 9, de 10 de enero de 2009).

36. (DOCV núm. 6056, de 14 de julio de 2008).

37. (BOE núm. 139, de 8 de junio de 2010).

38. Sólo es el caso de la Comunidad Valenciana y Andalucía.

39. Por ejemplo, Educación para Personas Adultas, Formación Profesional, Programas de Cualificación Profesional Inicial, Idiomas (castellano, euskera, enseñanza universitaria, documentación acreditativa de haber iniciado el procedimiento de homologación de títulos. 
40. Respecto al primer extremo se requiere documentación acreditativa de la Renta de Garantías e Ingresos o de la Renta Complementaria de Ingresos del Trabajo, así como documentación acreditativa de la Prestación Complementaria de Vivienda, de un Convenio de Inserción Social, plan de trabajo compartido, o bien informe de los Servicios Sociales de Base sobre los esfuerzos de inclusión de la persona solicitante, informe de entidades que trabajan en el ámbito de la inclusión.

41. (BOJA no 46 de 7 de marzo de 2012).

42. Conocimiento y respeto de los valores del Estatuto de Autonomía para Andalucía: Conocimiento y respeto de los valores de la Unión Europea. Conocimiento y respeto de los derechos humanos. Conocimiento y respeto de las libertades públicas y la democracia. Conocimiento y respeto de la tolerancia y la igualdad entre mujeres y hombres. Aprendizaje del castellano.

43. Instrucción $1 / 2012$ de la Dirección General para la inmigración del Departamento de Bienestar social y familia por la que se establecen los criterios generales para la elaboración de informes de extranjería competencia de la Generalitat Catalana.

44. BOCYL de 8 de julio de 2011.

45. DOCV no $^{\circ}$ 911, de 11/12/08.

46. $\mathrm{DOCV}^{\mathrm{0}}{ }^{\circ}$ 6056, de 14/07/09.

47. SOLANES CORELLA Ángeles, «¿Integrando por ley? De los contratos europeos de integración al compromiso de la ley autonómica Valenciana 15/2008», Revista española de derecho de extranjería y migratorio, 20, 2009, pp. 47-77, p. 68

48. Entidades locales, universidades, colegios profesionales, organizaciones no gubernamentales, sindicales, empresariales, de personas inmigrantes y asociaciones de interés general.

49. El contenido del Programa Conoce tus leyes: marco constitucional español, herramientas para el acceso al empleo, recursos para la integración, normativa española de extranjería.

50. Instrucción 1/2013, de 1 de febrero, de la Directora general de cooperación e inmigración, por la que se establecen los criterios generales para la elaboración de los informes de esfuerzo de integración para la renovación de autorizaciones de residencia (BOIB DEL 12/02/2013)

51. Disponible el contenido del programa en http://www.immigrabalears.com/spip.php? article495 (fecha de consulta 30 julio de 2013)

52. KOOPMANS, Ruud, "Trade-offs between equality and difference: Immigrant, integration, multiculturalismo and the Welfare State in cross-national perspective», Journal of Ethnic and Migration Studies, vol. 36, oㅡㄴ 2010, pp. 1-26, p. 24.

53. GUIRAUDON Virginie, «Contratos de integración para inmigrantes: tendencias comunes y diferencias en la experiencia europea ", Área: Demografía, Población y Migraciones Internacionales Real Instituto ElCano, ARI 43/ 2008. CARRERA Sergio, In search of the perfect citizen?: the intersection between integration, immigration, and nationality in the $E U$, Leiden, Boston, Martinus Nijhoff Publishers, 2009, p. 34.

54. HABERMAS Jürgen, La inclusión del otro. Traducción y estudio preliminar J.C. Velasco, Barcelona, Paidós, 1999, p. 189. 


\section{RESÚMENES}

Tras el Pacto europeo de Inmigración y Asilo 2008, España como país de destino de inmigración ha tratado de desarrollar una propia filosofía de integración observando la experiencia de otros modelos nacionales. Si bien por el momento a diferencia de lo que ocurre en otros países como Francia no existe un contrato de integración vinculante, a partir de la última ley de extranjería se ha reforzado el control « infra-droit » de la integración efectiva por medio de los informes sobre el esfuerzo de integración a nivel autonómico. Desde el 2010, la extensión de los informes sobre el esfuerzo de integración constituye un requisito determinante para la renovación de las autorizaciones de residencia y la reagrupación familiar, pero no están exentos de inconsistencias o inseguridad jurídica.

Après le Pacte européen sur l'immigration et l'asile de 2008, l'Espagne en tant que pays d'immigration a essayé de développer une philosophie d'intégration en observant l'expérience d'autres modèles nationaux. Bien que pour l'instant, contrairement à d'autres Etats comme la France, il n'y ait pas de mécanisme obligatoire, la dernière loi d'immigration a renforcé le contrôle «infra-droit» de l'intégration effective des étrangers par l'exigence de rapports d'intégration régionale. Depuis 2010, la longueur des rapports sur l'effort d'intégration est devenue une condition essentielle pour obtenir le renouvellement des permis de séjour et de regroupement familial. Toutefois, ces mesures ne sont pas dénuées d'incohérences et d'insécurité juridique.

\section{ÍNDICE}

Mots-clés: rapports, control infra-droit, l'Espagne, l'intégration, loi d'immigration, régions Palabras claves: informes, control infra-droit, España, integración, legislación de extranjería, autonomías

\section{AUTOR}

\section{ENCARNACIÓN LA SPINA}

Universitat de València

Encarnación La Spina est docteure en droit. Elle enseigne à l'Université de Valence et a effectué un post-doctorat à l'Université de Paris Ouest-Nanterre La Défense. 